\title{
Correction to: Seroprevalence of bovine brucellosis and associated risk factors in Nakasongola district, Uganda
}

\author{
James Bugeza ${ }^{1} \cdot$ Adrian Muwonge $^{2} \cdot$ Musso Munyeme $^{3} \cdot$ Phillip Lasuba $^{4} \cdot$ Jacques Godfroid $^{5} \cdot$ Clovice Kankya $^{6}$
}

Published online: 26 June 2019

(C) Springer Nature B.V. 2019

\section{Correction to: Tropical Animal Health and Production https://doi.org/10.1007/s11250-018-1631-6}

In the originally published article, the name of the fifth author was incorrectly presented as Godfroid Jacques. The correct name is Jacques Godfroid.

The original article has been corrected.

Publisher's note Springer Nature remains neutral with regard to jurisdictional claims in published maps and institutional affiliations.

The online version of the original article can be found at https://doi.org/ 10.1007/s11250-018-1631-6

\section{James Bugeza}

bugezaj@yahoo.com

1 National Livestock Resources Research Institute, Tororo, Uganda

2 Department of Genetics and Genomics-The Roslin Institute, University of Edinburgh, Edinburgh, UK

3 Department of Disease Control, University of Zambia, Lusaka, Zambia

4 Department of Animal Production, University of Juba, Juba, South Sudan

5 Department of Arctic and Marine Biology, University of Tromsø the Arctic University of Norway, Tromsø, Norway

6 Department of Biosecurity Ecosystems and Veterinary Public Health, Makerere University, Kampala, Uganda 